\title{
ISOMERISMO CIS-TRANS: DE WERNER AOS NOSSOS DIAS
}

\author{
Salete Linhares Queiroz \\ Departamento de Química Geral e Inorgânica - UNESP - CP 355 - 14800-900 - Araraquara - SP \\ Alzir Azevedo Batista \\ Departamento de Química - Universidade Federal de São Carlos - CP 676 - 13565-905- São Carlos - SP
}

Recebido em 17/9/96; aceito em 17/9/97

\begin{abstract}
CIS-TRANS ISOMERISM: FROM WERNER TO THE PRESENT DAYS: In coordination chemistry the study of geometrical isomerization and reactivity of specific isomers is a topic of major importance. The preparation of specific isomers often requires considerable complexity, and it is important to acquire a sense of what is involved in studying isomerism in laboratory. If it is difficult sometimes to prepare pure isomers, it is not easier to understand the mechanisms of isomerization reactions since studies on this subject have shown conflicting results and diferent interpretations on the same system have been reported in the literature. Although cis-trans isomerism in octahedral metal complexes is a common occurrence, there are relatively few studies reporting how these isomerizations occur. This paper gives an overview on cis-trans isomerization processes and identification of these species.
\end{abstract}

Keywords: complexes; isomerism; cis-trans.

\section{INTRODUÇÃO}

O fenômeno do isomerismo cis-trans em química inorgânica é capaz de ilustrar, em termos de número de exemplos conhecidos, o progresso da química inorgânica sintética. De fato, desde os estudos realizados por Werner no início deste século até os nossos dias, uma gama enorme de trabalhos envolvendo este tipo de isômeros vem sendo mencionada na literatura ${ }^{1-7}$.

Em se tratando de isômeros em complexos inorgânicos é sempre importante lembrar que a síntese dos mesmos, a comprovação de suas estruturas moleculares e a avaliação de suas propriedades, forneceram os argumentos decisivos para que Werner pudesse desenvolver e defender a sua teoria de coordenação. A importância destes estudos à sua época colocou Werner em posição de destaque na química de coordenação de tal maneira que o seu nome é virtualmente sinônimo deste campo $^{8}$. Investigações similares a respeito de novos isômeros e das suas reações de isomerização são relevantes na atualidade uma vez que estudos físicos, químicos e teóricos de algumas destas reações podem conduzir ao entendimento de mecanismos de rearranjo ${ }^{9,10}$, de diferenças estruturais entre os isômeros ${ }^{11}$ e da contrastante reatividade química de alguns pares isoméricos cis-trans $^{12,13}$. Estudos de isomerização cistrans de complexos quadrado planares de platina(II) e paládio(II) são intensamente realizados ${ }^{14-17}$, sendo esta atenção dispensada devido não somente ao aspecto mecanístico, como também pelo fato de que podem fornecer informações mais gerais a respeito da compreensão de reações de substituição neste tipo de complexos. É também importante observar que o estudo do isomerismo cis-trans envolvendo complexos de metais do grupo da platina, em particular, tem sido alvo de grande interesse devido à aplicabilidade de alguns isômeros desta classe de compostos como agentes antitumorais ${ }^{18}$. A estereoquímica de complexos de platina(II), por exemplo, é freqüentemente reconhecida como sendo de grande importância para a atividade biológica dos mesmos, pois o isômero cis do $\left[\mathrm{PtCl}_{2}\left(\mathrm{NH}_{3}\right)_{2}\right]$ é um agente antitumoral ativo, ao passo que o isômero trans é inativo ${ }^{18}$. Em contraste, o isômero cis do $\left[\mathrm{PdCl}_{2}\left(\mathrm{NH}_{3}\right)_{2}\right]$ é inativo ${ }^{19}$. Isto pode ser atribuído ao rápido isomerismo cis-trans de complexos de paládio(II) em solução. É verdade que o isômero trans da platina(II) é também mais estável que o isômero cis, na ordem de $13 \mathrm{~kJ} \mathrm{~mol}^{-1}$, entretanto, neste caso, o processo de isomerização é mais lento que para o similar de paládio(II) ${ }^{19}$. Investigações a respeito de distintas atividades catalíticas para os vários isômeros possíveis de um complexo são também realizadas e impulsionam o estudo destas espécies ${ }^{20,21}$.

Algumas formas de obtenção de isômeros cis-trans de complexos de metais do grupo da platina, os métodos físicos usados na elucidação das suas estruturas, suas reações de isomerização e propostas mecanísticas serão aqui revistas.

Berzelius propôs em 1823 que substâncias de mesma composição, mas que apresentassem diferentes propriedades, fossem chamadas de isoméricas, do grego $1 \sigma o \mu \varepsilon \rho \eta \zeta$ (composto de partes iguais), nascendo assim o conceito de isomerismo ${ }^{22}$. Embora o isomerismo possa ser dividido em vários tipos, podese afirmar que existem apenas duas formas básicas: Isomerismo Estrutural e Estereoisomerismo.

\section{ISOMERISMO ESTRUTURAL}

O qual é também chamado de constitucional ou de posição, ocorre quando duas ou mais moléculas têm a mesma fórmula empírica mas os seus constituintes são arranjados diferentemente; existe diferença na seqüência de ligação átomo a átomo. Existem várias formas deste tipo de isomerismo, sendo os de hidratação, de polimerização, de coordenação e de ligação os mais freqüentemente abordados na literatura ${ }^{23}$.

\section{ESTEREOISOMERISMO}

Ocorre quando dois ou mais compostos têm a mesma fórmula empírica e a mesma seqüência de ligação átomo a átomo mas estes diferem no seu arranjo espacial. $\mathrm{O}$ estereoisomerismo, por sua vez, é subdividido em isomerismo geométrico e isomerismo óptico ${ }^{23,24}$. Nesta breve revisão nos deteremos no conceito de isomerismo geométrico.

$\mathrm{O}$ isomerismo geométrico do tipo cis-trans é observado quando dois grupos iguais ocupam posições adjacentes (cis) ou opostas (trans) um em relação ao outro em um complexo ${ }^{24}$. Um grande número de exemplos ilustram esta situação na geometria octaédrica, podendo-se citar o exemplo clássico dos 
isômeros violeta (cis) e verde (trans) do $\left[\mathrm{Co}\left(\mathrm{NH}_{3}\right)_{4} \mathrm{Cl}_{2}\right]^{+} \mathrm{Cl}^{-}$, investigados por Werner ${ }^{23}$. Na geometria quadrado planar isômeros cis e trans são também comuns, sendo a platina e o paládio metais onde observa-se com freqüência este fenômeno ${ }^{14-17}$.

Uma outra nomenclatura também bastante empregada quando se trata de isômeros geométricos cita a posição cis ou trans de cada um dos ligantes ou pontos de coordenação iguais, um em relação ao outro, presentes na molécula. Assim, os 5 isômeros possíveis do complexo $\left[\mathrm{Os}\left(\mathrm{C}_{5} \mathrm{H}_{4} \mathrm{NS}\right)_{2}\left(\mathrm{PPh}_{3}\right)_{2}\right]$ são descritos como cct, ttt , ctc, tcc, ccc, de acordo com a tríade de pares doadores $(\mathrm{N}, \mathrm{N})-(\mathrm{S}, \mathrm{S})-(\mathrm{P}, \mathrm{P})^{25}$, conforme ilustra a figura 1 .

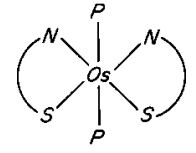

$c c t$

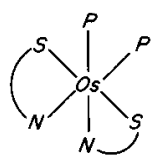

ctc

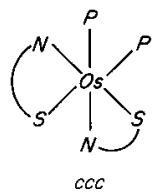

Figura 1. Isômeros geométricos do complexo $\left[\mathrm{Os}\left(\mathrm{C}_{5} \mathrm{H}_{4} \mathrm{NS}\right)_{2}\left(\mathrm{PPh}_{3}\right)_{2}\right]^{25}$.

Um outro tipo de isomerismo geométrico é o facial ( $f a c)$ e o meridional (mer). Compostos de fórmula $\left[\mathrm{MK}_{3} \mathrm{~L}_{3}\right]$, onde $\mathrm{K} \mathrm{e}$ L são ligantes monodentados, por exemplo, podem apresentar os isômeros fac e mer. O termo fac designa um composto no qual três átomos doadores idênticos estão na face do octaedro. $\mathrm{O}$ termo mer designa o outro isômero, no qual três grupos idênticos estão no meridiano do octaedro ${ }^{24}$.

Uma ampla investigação de isômeros geométricos envolve a obtenção dos mesmos e suas caracterizações por métodos físicos diversos. Na realização destes estudos é comum a obtenção de misturas de isômeros, sendo suas separações também de primordial importância. $\mathrm{O}$ entendimento do mecanismo de formação e eventualmente de interconversão entre pares isoméricos é também relevante, bem como a análise de suas possíveis aplicações, seja como agentes antitumorais ou catalíticos, por exemplo.

\section{MÉTODOS DE OBTENÇÃO DE ISÔMEROS GEOMÉTRICOS CIS-TRANS}

Isômeros geométricos cis-trans podem ser obtidos nas suas formas puras por meio de rotas sintéticas distintas ou como misturas, fazendo-se, quando possível, a separação dos mesmos.

A síntese de uma série de isômeros geométricos pode envolver grandes dificuldades e um considerável volume de trabalho, uma vez que a estereoquímica dos isômeros é muitas vezes controlada por pequenas alterações nas condições de reação, que precisam ser cuidadosamente selecionadas e rigorosamente mantidas ${ }^{26,27}$. Temperatura, solvente e tempo de reação costumam apresentar-se como fatores determinantes na obtenção de isômeros geométricos distintos. Na preparação dos isômeros geométricos cis e trans do complexo $\left[\mathrm{PtCl}_{2}\right.$ $\left.\left(\mathrm{Ph}_{2} \mathrm{PCH}_{2} \mathrm{C}_{4} \mathrm{H}_{7} \mathrm{O}\right)_{2}\right]$ em acetona, por exemplo, um tempo de reação de 30 minutos conduz à formação do isômero cis, enquanto que o prolongamento deste período até 67 horas conduz à formação do isômero $\operatorname{trans}^{28}$, conforme ilustra o esquema reacional da figura 2 .

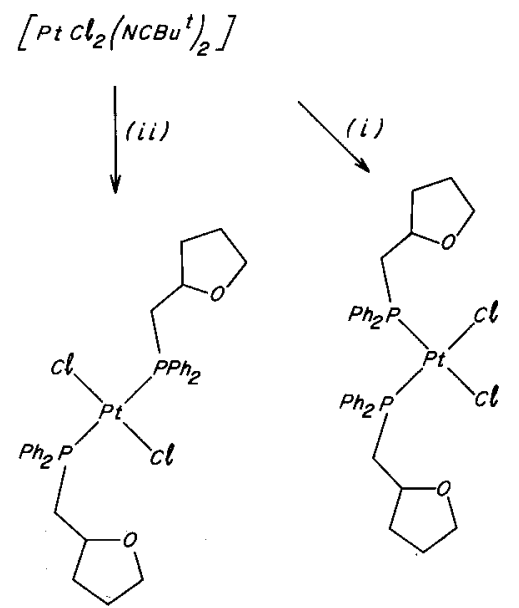

Figura 2. Esquema reacional da preparação dos isômeros cis- $e$ trans[PtCl ${ }_{2}\left(\mathrm{Ph}_{2} \mathrm{PCH}_{2} \mathrm{C}_{4} \mathrm{H}_{7} \mathrm{O}\right)_{2}$ ] onde (i) adição de 2 equivalentes do ligante $\mathrm{Ph}_{2} \mathrm{PCH}_{2} \mathrm{C}_{4} \mathrm{H}_{7} \mathrm{O}$ em acetona com tempo de agitação de 30 minutos e (ii) adição de 2 equivalentes do ligante $\mathrm{Ph}_{2} \mathrm{PCH}_{2} \mathrm{C}_{4} \mathrm{H}_{7} \mathrm{O}$ em acetona com tempo de agitação de 67 horas $^{28}$.

A reação do complexo de $\mathrm{Rh}(\mathrm{I}),\left[\mathrm{Rh}(\mathrm{SPh})\left(\mathrm{PMe}_{3}\right)_{3}\right]$, com $\mathrm{HSPh}$ conduz à formação de dois complexos isoméricos de $\mathrm{Rh}(\mathrm{III})^{29}$, conforme ilustra a figura 3 . A obtenção de um produto ou de outro é também dependente do tempo de reação empregado, uma vez que quando $\mathrm{HSPh}$ é adicionado a uma solução de hexano contendo o complexo $\left[\mathrm{Rh}(\mathrm{SPh})\left(\mathrm{PMe}_{3}\right)_{3}\right]$ o isômero cis,mer- $\left[\mathrm{RhH}(\mathrm{SPh})_{2}\left(\mathrm{PMe}_{3}\right)_{3}\right]$ precipita imediatamente como um sólido marron e é filtrado e seco à vácuo. A agitação desta mistura reacional por sete dias causa o desaparecimento do isômero cis,mer- $\left[\mathrm{RhH}(\mathrm{SPh})_{2}\left(\mathrm{PMe}_{3}\right)_{3}\right]$ e a formação de cristais amarelos do isômero trans, mer- $\left[\mathrm{RhH}(\mathrm{SPh})_{2}\left(\mathrm{PMe}_{3}\right)_{3}\right]$.

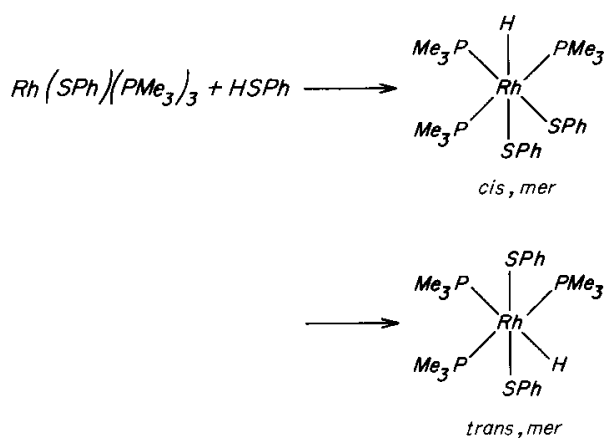

Figura 3. Complexos isoméricos cis,mer- $e$ trans, mer- $\left[\mathrm{RhH}(\mathrm{SPh})_{2}\left(\mathrm{PMe}_{3}\right)_{3}\right]^{29}$.

Fatores como solvente e temperatura de reação, por sua vez, mostram-se importantes na síntese dos isômeros cis-e trans$\left[\mathrm{RuCl}_{2}(\mathrm{CO})_{2}(\mathrm{R}-\mathrm{Pyca})\right]$, onde R-Pyca são ligantes piridinacarbaldimina ${ }^{27}$. A reação de $n$ equivalentes de ligantes bidentados R-Pyca ( $\mathrm{R}=$ isopropil (a), metoxietil (b), isopropoxipropil (c)) com o polímero $\left[\mathrm{RuCl}_{2}(\mathrm{CO})_{2}\right]_{\mathrm{n}} \mathrm{em} \mathrm{CH}_{2} \mathrm{Cl}_{2}$, à temperatura ambiente, leva à formação dos produtos trans- $\left[\mathrm{RuCl}_{2}(\mathrm{CO})_{2}\right.$ (R-Pyca)] (1) em 75-80\% de rendimento. À temperatura de refluxo em tolueno ou xileno o isômero cis- $\left[\mathrm{RuCl}_{2}(\mathrm{CO})_{2}\right.$ (R-Pyca)] (2) é formado com 85-95\% de rendimento. (1) isomeriza-se à temperatura de refluxo em xileno ao produto (2). 
As sínteses seletivas destes complexos e a isomerização encontram-se ilustradas na figura 4 .

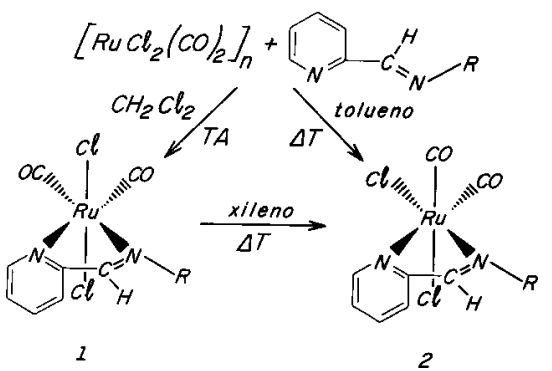

Figura 4. Sinteses seletivas dos isômeros trans- e cis- $\left[\mathrm{RuCl} \mathrm{l}_{2}(\mathrm{CO})_{2}(\mathrm{R}-\right.$ Pyca)] a partir da reação de $\mathrm{n}$ equivalentes de ligante bidentado $R$ Pyca com o polímero $\left[\mathrm{RuCl}_{2}(\mathrm{CO})_{2}\right]_{n}:$ 1) em $\mathrm{CH}_{2} \mathrm{Cl}_{2}$ à temperatura ambiente (18 horas) e 2) em tolueno à temperatura de refluxo $(20$ horas). Isomerização térmica do trans- $\left[\mathrm{RuCl}_{2}(\mathrm{CO})_{2}(\mathrm{R}-\mathrm{Pyca})\right]$ ao correspondente isomero cis- por refluxo em xileno durante 20 horas $^{27}$.

A exemplo do que ocorre com o par isómerico cis-trans $\left[\mathrm{RuCl}_{2}(\mathrm{CO})_{2}(\mathrm{R}-\mathrm{Pyca})\right]^{27}$, onde verifica-se um processo de isomerização térmica, a obtenção de um dos constituintes do par através da interconversão de um deles é comum e é algumas vezes alcançada por reações de isomerização térmica, fotoquímica ou induzida por oxidação ou redução que serão discutidas a seguir.

Conforme mencionado anteriormente, a obtenção de misturas é também um fato corriqueiro que dificulta o isolamento de uma série de isômeros. A obtenção dos complexos cis- e trans$\left[\mathrm{PtCl}_{2}(\mathrm{NCR})_{2}\right]\left(\mathrm{R}=\mathrm{C}_{6} \mathrm{H}_{5}, \mathrm{p}-\mathrm{CH}_{3} \mathrm{C}_{6} \mathrm{H}_{4}, \mathrm{p}-\mathrm{CF}_{3} \mathrm{C}_{6} \mathrm{H}_{4}, \mathrm{o}-\mathrm{CH}_{3} \mathrm{C}_{6} \mathrm{H}_{4}\right.$, $\left.\mathrm{CH}_{3}, \mathrm{CH}_{3} \mathrm{CH}_{2}, \mathrm{CH}_{3} \mathrm{CH}_{2} \mathrm{CH}_{2},\left(\mathrm{CH}_{3}\right)_{2} \mathrm{CH},\left(\mathrm{CH}_{3}\right)_{3} \mathrm{C}\right)$ ilustra bem este fato $^{30}$. Suas sínteses são realizadas por dois métodos, ilustrados nas equações (1) e (2), mostradas a seguir, e ambos conduzem a misturas de isômeros cis e trans em diferentes proporções dependendo das condições experimentais como tempo, temperatura de reação e, inclusive, dos radicais $\mathrm{R}$, o que dificulta prever o(s) isômero(s) a ser(em) obtido(s) em determinado sistema:

$$
\begin{aligned}
& {\left[\mathrm{K}_{2} \mathrm{PtCl}_{4}\right]+\mathrm{RCN} \rightarrow \text { cis- e/ou trans- }\left[\mathrm{PtCl}_{2}(\mathrm{NCR})_{2}\right]} \\
& {\left[\mathrm{PtCl}_{2}\right]+\mathrm{RCN} \rightarrow \text { cis- e trans- }\left[\mathrm{PtCl}_{2}(\mathrm{NCR})_{2}\right]}
\end{aligned}
$$

A separação dos vários isômeros que compõem uma determinada mistura é desejável uma vez que possibilita o estudo sobre as propriedades físicas e químicas dos mesmos, bem como das suas distintas reatividades. Considerando-se que da configuração geométrica de um complexo depende, muitas vezes, o curso de reações tais como substituição nucleofílica, transferência de elétrons, adição oxidativa, eliminação redutiva, decomposição térmica e interação com moléculas biológicas pode-se esperar contrastantes reatividades químicas e aplicações distintas para diferentes isômeros de um mesmo complexo ${ }^{12,31-34}$.

$\mathrm{O}$ deslocamento do tetraidrotiofeno(tht) dos isômeros cis- e trans- $\left[\mathrm{Pd}\left(\mathrm{C}_{6} \mathrm{~F}_{5}\right)_{2}(\text { tht })_{2}\right]$ por nucleófilos, por exemplo, foi investigado com o objetivo de se obter maiores informações com relação à reatividade dos dois isômeros. As reações dos trans- e cis$\left[\operatorname{Pd}\left(\mathrm{C}_{6} \mathrm{~F}_{5}\right)_{2}(\mathrm{tht})_{2}\right]$ com piridina foram examinadas por ressonância magnética nuclear de próton, verificando-se que as reações de substituição ocorrem com retenção de geometria e que o isômero cis reage mais rapidamente que o isômero trans ${ }^{35}$.

Alguns complexos de $\mathrm{Ru}(\mathrm{III})$ contendo o ligante dimetilsulfóxido são usados como precusores na síntese de compostos antitumorais ativos. Entretanto, informações sobre seus aspectos estruturais, principalmente via espectroscopia de ressonância magnética nuclear, são dificultadas em vista de seu paramagnetismo. Para contornar esta eventual limitação, estudos com isômeros isoestruturais mer-cis- e mer-trans-[ $\left.\mathrm{RhCl}_{3}(\mathrm{dmso}-\mathrm{S})_{2}(\mathrm{dmso}-\mathrm{O})\right]$, por exemplo, foram realizados considerando-se o aspecto vantajoso de que o Rh(III) é diamagnético ${ }^{36}$.

Atividades catalíticas distintas para diferentes espécies isoméricas foram também sugeridas ${ }^{20,21}$, sendo reportado por Batista e colaboradores que entre os isômeros ttt, tcc e ctc ( nomenclatura de acordo com a tríade de pares doadores $(\mathrm{Cl}, \mathrm{Cl})$ $(\mathrm{CO}, \mathrm{CO})-(\mathrm{N}-\mathrm{N})$ ) do complexo $\left[\mathrm{RuCl}_{2}(\mathrm{CO})_{2}(\mathrm{MeIm})_{2}\right]$, onde MeIm = 1-metilimidazol, apenas o isômero ttt catalisa reações de hidrogenação/isomerização do álcool alílico em presença de 1 atm de hidrogênio a $70^{\circ} \mathrm{C}^{21}$.

Os métodos de cristalização e a técnica de cromatografia são os recursos mais comumente usados para a separação dos componentes de misturas isoméricas. Os isômeros cis e trans para cada complexo bis(nitrila) sintetizados a partir dos 2 métodos ilustrados nas equações (1) e (2), por exemplo, foram separados por cristalização fracionada considerando-se suas diferentes solubilidades, onde as formas cis são geralmente menos solúveis em solventes não ou ligeiramente polares ${ }^{30}$. A técnica de cristalização fracionada foi também o método empregado para separação dos complexos cis- e trans- $\left[\mathrm{Pd}\left(\mathrm{C}_{6} \mathrm{~F}_{5}\right)_{2}(\text { tht })_{2}\right]$, onde tht $=$ tetraidrotiofeno ${ }^{35}$. Os isômeros cis- e trans- $\left[\mathrm{RuCl}_{2}(\mathrm{dppen})_{2}\right]$, onde dppen $=$ cis-1,2-bis(difenilfosfina) etileno, foram sintetizados como uma mistura e também separados com base nas diferenças de solubilidade: o produto bruto contendo os dois isômeros foi agitado em clorofórmio e verificou-se a formação de um precipitado amarelo que foi filtrado, lavado com éter e seco à vácuo. Este sólido foi identificado como sendo o isômero cis. O isômero trans foi obtido pela concentração do filtrado até aproximadamente $3 \mathrm{~mL}$ e precipitação com éter ${ }^{37}$.

O emprego da cromatografia na separação de isômeros geométricos é corriqueiro e a separação dos isômeros cis- e trans$\left[\mathrm{Pt}(\mathrm{L}-\mathrm{Met}-\mathrm{S}, \mathrm{N})_{2}\right]$, onde L-Met-S,N = L-metionina, usando HPLC de fase reversa realizada por Sadler e colaboradores é um exemplo recente ${ }^{38}$. Separações empregando-se colunas cromatográficas são também freqüentemente citadas na literatura, sendo os complexos cis- e trans-[RuI(Hdmo $\left.)_{2}(\mathrm{NO})\right]$, onde $\mathrm{Hdmo}=2,3$ butanodiona dioxima, separados por este método ${ }^{39}$. A mistura de isômeros de $\left[\mathrm{RuI}(\mathrm{Hdmo})_{2}(\mathrm{NO})\right]$ foi preparada refluxando-se em etanol tricloronitrosilrutênio(III), Hdmo e iodeto de sódio por 14 horas. Em seguida o solvente foi evaporado e o resíduo dissolvido em diclorometano, filtrando-se os materiais insolúveis. A solução foi eluída em coluna de sílica-gel (Wakogel C-300, $\phi$ $4 \mathrm{~cm} \times 20 \mathrm{~cm}$ ) com diclorometano. A primeira e a segunda fração foram evaporadas separadamente em evaporador rotatório levando à obtenção de dois produtos vermelhos. O produto da primeira banda de adsorção foi identificado como sendo o isômero trans, e o da segunda banda como sendo o isômero cis. Os isômeros cis e trans do complexo $\left[\mathrm{RhCl}_{2}(\mathrm{dmap})_{2}\right]^{+}$, onde dmap $=1,3$-bis (dimetilarsino)propano, foram separados por coluna cromatográfica de troca iônica ${ }^{40}$.

As relações do isomerismo geométrico de complexos metálicos quadrado planares e octaédricos com os seus valores de $\mathrm{R}_{\mathrm{F}}$ obtidos por cromatografia de papel foram também exaustivamente investigadas, estabelecendo-se que de uma maneira geral, em sistemas envolvendo um único solvente, os isômeros trans exibem maiores valores de $\mathrm{R}_{\mathrm{F}}$ que os correspondentes isômeros cis nos complexos octaédricos e quadrado planares. Ordem inversa é observada quando misturas de solventes são usadas. Esta diferença de comportamento pode ser usada para separação de isômeros. Isto se deve ao fato de que no uso de um único solvente o mecanismo provavelmente envolve adsorção, enquanto no caso de mistura de solventes, o processo de partição deve estar presente en $^{41,42}$.

\section{ALGUMAS TÉCNICAS USADAS NA ELUCIDAÇÃO DE ESTRUTURAS DE ISÔMEROS CIS-TRANS}

Considerando-se as técnicas disponíveis no início do século vinte, pode-se concluir que uma enorme perspicácia e uma 
grande dose de astúcia foram necessárias a Werner e colaboradores na formulação do modelo original da teoria de coordenação. Werner estabeleceu os fundamentos experimentais da mesma usando os mais elementares e despretenciosos tipos de equipamentos. Munido apenas de aparatos primitivos, como espátula de platina e vidros de relógio, este pesquisador submeteu seus complexos às mais diversas reações químicas e transformações físicas. $\mathrm{Na}$ época, as informações acessíveis mais importantes incluíam estequiometria e cor, número e natureza de isômeros e algumas medidas físicas, tais como condutância molar em solução aquosa e determinação de peso molecular ${ }^{43}$.

Com o desenvolvimento de métodos instrumentais como espectroscopia de absorção na região do infravermelho e ultravioleta/visível, espectroscopia de ressonância magnética multinuclear e de raios-X, entre outros, o estudo e a caracterização de isômeros geométricos tornou-se menos espinhosa, uma vez que o uso de uma destas técnicas ou a combinação de mais de uma delas pode fornecer irrefutáveis indícios da geometria dos mesmos.

A espectroscopia de absorção na região do infravermelho, por exemplo, fornece subsídios para que se possa distinguir entre os isômeros cis e trans de complexos de paládio e platina uma vez que existem marcantes diferenças em seus espectros ${ }^{44-46}$. Indicações satisfatórias da estereoquímica dos isômeros trans- e cis$\left[\mathrm{Pd}\left(\mathrm{C}_{6} \mathrm{~F}_{5}\right)_{2}(\mathrm{tht})_{2}\right]$ onde tht $=$ tetraidrotiofeno, são provenientes dos seus espectros de absorção na região do infravermelho. $\mathrm{O}$ complexo cis mostra duas bandas a 789 e $780 \mathrm{~cm}^{-1}$ enquanto que o isômero trans apresenta uma única banda a $772 \mathrm{~cm}^{-1} 35$. A região de $800-600 \mathrm{~cm}^{-1}$ tem também sido investigada em detalhes por vários autores para complexos do tipo cis-e trans$\left[\mathrm{PtCl}_{2}\left(\mathrm{NCC}_{6} \mathrm{H}_{5}\right)_{2}\right]$. A forma cis deste tipo de complexo exibe vibrações de deformação fora do plano $\delta(\mathrm{CH})$ em 680,692 $\mathrm{cm}^{-1}$ e $754,776 \mathrm{~cm}^{-1}$, enquanto que a forma trans apresenta apenas duas bandas fortes a $683 \mathrm{e}^{2} 762 \mathrm{~cm}^{-1} 30,47,48$. A estereogeometria trans e cis de dicloro complexos de Pt(II) e de Pd(II) pode ser usualmente deduzida pela presença de uma ou duas bandas, respectivamente, na região de $\mathrm{Pt}-\mathrm{Cl}$ e $\mathrm{Pd}_{-} \mathrm{Cl}^{46}$. Os isômeros cis e trans do tert-butilaminadicloro(dimetilsulfóxido) platina(II), por exemplo, apresentam duas bandas de estiramento $\mathrm{Pt}-\mathrm{Cl}$ a 331 e $305 \mathrm{~cm}^{-1}$ e uma banda de estiramento $\mathrm{Pt}-\mathrm{Cl}$ a $340 \mathrm{~cm}^{-1}$, respectivamente ${ }^{49}$.

Além da técnica de espectroscopia de absorção na região do infravermelho, muitos outros métodos podem ser usados com o objetivo de se distinguir os isômeros cis e trans de complexos de platina(II $)^{50}$. Para identificação de complexos do tipo $\left[\left(\mathrm{R}_{3} \mathrm{P}\right)_{2} \mathrm{PtX}_{2}\right]$ a magnitude da constante de acoplamento platina-fósforo no espectro de $\mathrm{RMN}{ }^{31} \mathrm{P}\left\{{ }^{1} \mathrm{H}\right\}$ é uma indicação da geometria ${ }^{51,52}$. Os complexos cis apresentam tipicamente ${ }^{1} \mathrm{~J}_{\mathrm{PtP}}$ $>3000 \mathrm{~Hz}$, enquanto que os complexos trans apresentam ${ }^{1} \mathrm{~J}_{\mathrm{PtP}}$ $<2400 \mathrm{~Hz}$. Informações deste tipo foram úteis na determinação das estruturas de cis e trans complexos de $\mathrm{Pt}(\mathrm{II})$ com as cianoetilfosfinas, $\mathrm{P}\left(\mathrm{CH}_{2} \mathrm{CH}_{2} \mathrm{CN}\right)_{3}(\mathrm{CEP}), \mathrm{C}_{6} \mathrm{H}_{5} \mathrm{P}\left(\mathrm{CH}_{2} \mathrm{CH}_{2} \mathrm{CN}\right)_{2}$ $(\mathrm{PhCEP})$ e $\left(\mathrm{C}_{6} \mathrm{H}_{5}\right)_{2} \mathrm{PCH}_{2} \mathrm{CH}_{2} \mathrm{CN}\left(\mathrm{Ph}_{2} \mathrm{CEP}\right)^{53}$. É interessante mencionar que o complexo $\left[\mathrm{PtCl}_{2}(\mathrm{CEP})_{2}\right]$ teve sua geometria determinada por Waltson e Whyman ${ }^{54}$ em 1968 como sendo do tipo trans, tomando-se como base a observação de apenas uma vibração $v_{\mathrm{PtCl}}$ na região de baixa freqüência no espectro de absorção na região do infravermelho. Uma investigação posterior da geometria deste complexo realizada por Holt e Nel$\operatorname{son}^{53}$ aliando espectroscopia de absorção na região do infravermelho com ressonância magnética multinuclear mostrou a existência de uma mistura de isômeros trans - e cis$\left[\mathrm{PtCl}_{2}(\mathrm{CEP})_{2}\right]$. O espectro de $\mathrm{RMN}{ }^{31} \mathrm{P}\left\{{ }^{1} \mathrm{H}\right\}$ apresenta duas ressonâncias com satélites associados (Figura 5), uma delas a $\delta$ 4,84 e a outra a $\delta 10,47$, indicando uma mistura de isômeros cis e trans. Os satélites correspondentes ao acoplamento do fosfóro 31 com o isótopo 195 da platina, com atividade na ressonância magnética nuclear por possuir spin 1/2, apresentam uma constante de acoplamento ${ }^{1} J_{\mathrm{PtP}}$ de $3489 \mathrm{~Hz}$ e ${ }^{1} \mathrm{~J}_{\mathrm{PtP}}$ de

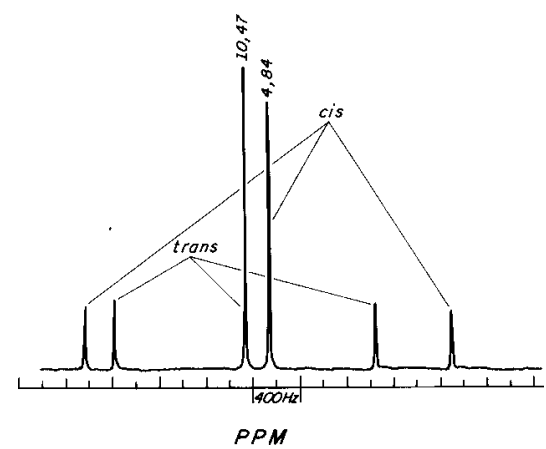

Figura 5. Espectro de $\mathrm{RMN}^{31} \mathrm{P}\left\{{ }^{1} \mathrm{H}\right\} 40,26-\mathrm{MHz}$ de $\left[\mathrm{PtCl}_{2}(\mathrm{CEP})_{2}\right] \mathrm{em}$ $\mathrm{Me}_{2} \mathrm{SO}$ a $298 \mathrm{~K}^{53}$.

$2476 \mathrm{~Hz}$. A ressonância a $\delta 4,84\left({ }^{1} \mathrm{~J}_{\mathrm{PtP}}\right.$ de $\left.3489 \mathrm{~Hz}\right)$ foi atribuída ao isômero cis, e a ressonância a $\delta 10,47\left({ }^{1} \mathrm{~J}_{\mathrm{PtP}}\right.$ de $\left.2476 \mathrm{~Hz}\right)$, embora com um valor de ${ }^{1} J_{\mathrm{PtP}}$ pouco superior ao valor limite citado anteriormente de $2400 \mathrm{~Hz}$, ao isômero trans . No espectro de RMN ${ }^{195} \mathrm{Pt}\left\{{ }^{1} \mathrm{H}\right\}$ (Figura 6) dois tripletes são observados, também indicativos da existência de duas espécies, cada uma contendo dois ligantes fosfínicos equivalentes. Os resultados deste último experimento deixam claras as vantagens, ou mesmo a necessidade, do uso de mais de uma técnica na tentativa de determinação da geometria de isômeros, uma vez que ambiguidades eventualmente geradas pelo uso de um método instrumental podem ser eliminadas quando se considera também resultados extraídos de outras técnicas.

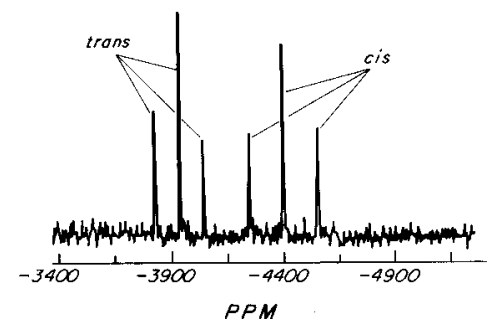

Figura 6. Espectro de $\mathrm{RMN}{ }^{195} \mathrm{Pt}\left\{{ }^{1} \mathrm{H}\right\} 21,30 \mathrm{MHz}$ de $\left[\mathrm{PtCl}_{2}(\mathrm{CEP})_{2}\right]$ em $\mathrm{Me}_{2} \mathrm{SO}$ a $298 \mathrm{~K}^{53}$.

A combinação das técnicas de absorção na região do infravermelho e ressonância magnética multinuclear, por exemplo, tem sido constantemente usada na tentativa de se determinar as geometrias dos mais diversos isômeros, podendo-se citar trabalhos realizados por Nelson e Krassowski ${ }^{20,55}$ com complexos de rutênio contendo monofosfinas. Quando soluções de $\mathrm{RuCl}_{3} .3 \mathrm{H}_{2} \mathrm{O}$ em 2-metoxietanol são refluxadas sob monóxido de carbono e uma monofosfina é adicionada, complexos do tipo $\left[\mathrm{RuCl}_{2}(\mathrm{CO})_{2} \mathrm{P}_{2}\right]$ são prontamente formados. Estes complexos podem ter potencialmente uma das cinco formas isoméricas ilustradas na figura 7 e cada uma delas pode ser distinguida das demais pela combinação de técnicas espectroscópicas.

Observações dos estiramentos $\mathrm{C} \equiv \mathrm{O}$ e $\mathrm{Ru}-\mathrm{Cl}$ na região do infravermelho e de dados fornecidos por $\operatorname{RMN}{ }^{31} \mathrm{P}\left\{{ }^{1} \mathrm{H}\right\},{ }^{1} \mathrm{H}$ e ${ }^{13} \mathrm{C}\left\{{ }^{1} \mathrm{H}\right\}$ definem as estruturas de cada um dos produtos obtidos. Para o caso particular onde $\mathrm{P}=$ benzilfosfinas ${ }^{55}$ apenas os isômeros ttt e cct foram isolados. O complexo cct apresenta duas vibrações fortes em 1980 e $2050 \mathrm{~cm}^{-1}$ devidas aos grupos carbonilas mutuamente em cis, ao passo que o complexo ttt apresenta apenas uma vibração forte em $2015 \mathrm{~cm}^{-1}$ devida aos grupos carbonila mutuamente em trans. Ambos os isômeros apresentam vibrações na região de $270-355 \mathrm{~cm}^{-1}$ devido a $v_{\mathrm{RuCl}}$, uma para o complexo ttt e duas para o cct. Os dados extraídos dos espectros de RMN ${ }^{1} \mathrm{H} \mathrm{e}{ }^{13} \mathrm{C}\left\{{ }^{1} \mathrm{H}\right\}$ para estes complexos mostraram-se em concordância com aqueles fornecidos pelos 

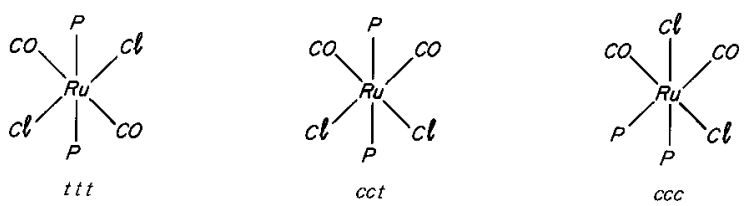

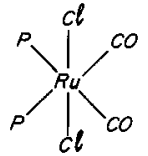

tcc

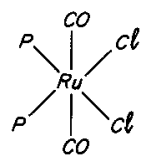

ctc
Figura 7. Isômeros geométricos do complexo $\left[\mathrm{RuCl}_{2}(\mathrm{CO})_{2}(\mathrm{P})_{2}\right]^{20,55}$.

espectros de absorção na região do infravermelho e são de fácil análise uma vez que é reconhecido que em complexos de metais de transição contendo duas fosfinas terciárias com grupos metileno ligados ao fósforo o aparecimento da ressonância do metileno nos espectros de RMN ${ }^{1} \mathrm{H}$ e ${ }^{13} \mathrm{C}\left\{{ }^{1} \mathrm{H}\right\}$ é determinada pela magnitude de ${ }^{2} \mathrm{~J}_{\mathrm{P}-\mathrm{P}}{ }^{56}$. Quando os núcleos de fósforo estão mutuamente em cis, ${ }^{2} \mathrm{~J}_{\mathrm{P}-\mathrm{P}}$ é geralmente menor que $80 \mathrm{~Hz}$ e a ressonância dos metilenos aparece como um dubleto. Se os dois núcleos de fósforo estão mutuamente em trans, então ${ }^{2} \mathbf{J}_{\mathrm{P} \text { - }}$ p é geralmente $500 \mathrm{~Hz}$ ou maior e a ressonância do metileno aparece como um tripleto $1: 2: 1$. Cada um dos complexos apresentou um único sinal nos seus espectros de RMN ${ }^{31} \mathrm{P}\left\{{ }^{1} \mathrm{H}\right\}$, e a ressonância do isômero trans apresentou-se em campo mais baixo que do isômero cis. Este fato pode ser atribuído ao efeito trans competitivo. Neste caso, quando ligantes bons receptores $\pi$, como o $\mathrm{CO}$, encontram-se trans um em relação ao outro, como no isômero ttt, estes competem com a mesma intensidade pelos elétrons do centro metálico, deixando-o rico em densidade eletrônica. Como consequiência os átomos de fósforo das fosfinas ficam mais blindados, apresentando deslocamentos químicos mais altos que os mostrados nos isômeros tipo cct, onde o efeito trans competitivo não é observado ${ }^{21}$.

Os isômeros cis- e trans- $\left[(\mathrm{bpy})_{2} \mathrm{Os}(\mathrm{O})_{2}\right]\left(\mathrm{ClO}_{4}\right)_{2}$, reportados por Meyer e colaboradores ${ }^{57}$, tiveram suas estruturas também determinadas a partir da análise dos dados de espectroscopia na região do infravermelho e ressonância magnética nuclear de ${ }^{1} \mathrm{H}$. O complexo cis- apresenta duas bandas na região de $\mathrm{v}(\mathrm{Os}=\mathrm{O})$ em 883 e $863 \mathrm{~cm}^{-1}$, os quais são atribuídos aos estiramentos simétrico e assimétrico $\mathrm{Os}=\mathrm{O}$, respectivamente, e são indicativos de estrutura cis- dioxo. O complexo trans mostra uma única banda nesta região a $872 \mathrm{~cm}^{-1}$, indicativo de estrutura trans-dioxo. Os espectros de $\mathrm{RMN}{ }^{1} \mathrm{H}$ do cis$\left[(\text { bpy })_{2} \mathrm{Os}(\mathrm{O})_{2}\right]^{2+}$ em $\mathrm{CD}_{3} \mathrm{CN}$ e do trans- $\left[(\mathrm{bpy})_{2} \mathrm{Os}(\mathrm{O})_{2}\right]^{2+} \mathrm{em}$ $\mathrm{Me}_{2} \mathrm{SO}-\mathrm{d}_{6}$ foram também obtidos. O espectro do complexo cis é consistente com a presença de ressonância para oito prótons não equivalentes enquanto que o isômero trans mostra ressonância para quatro prótons não equivalentes. Esta alteração no padrão destes espectros é consistente com a mudança da simetria $C_{2}$ para $D_{2 h}$ com a isomerização de cis para trans.

Complexos isoméricos de ósmio foram novamente reportados por Meyer e colaboradores ${ }^{58}$ recentemente, apresentandose na forma trans- e cis- $\left[\mathrm{OsCl}_{2}(\operatorname{tpy})(\mathrm{N})\right]^{+}$, onde tpy $=$ $2,2^{\prime}: 6^{\prime}, 2^{\prime \prime}$ - terpiridina, sendo a diferença estrutural entre estes isômeros claramente estabelecida a partir da análise dos espectros de $\mathrm{RMN}{ }^{1} \mathrm{H}$, ilustrados na figura 8 . A ressonância dos prótons orto magneticamente equivalentes $\left(6,6^{\prime \prime}\right)$ nos anéis externos do ligante tpy é sensível à estereoquímica do complexo. Em $\mathrm{CD}_{3} \mathrm{CN}$ eles aparecem a 9 ppm no isômero trans, e 9,8 ppm no isômero cis. O acentuado deslocamento químico para campo baixo no isômero cis provavelmente deve-se a uma blindagem menos efetiva dos prótons nos anéis pela densidade eletrônica no orbital $\mathrm{d}_{\mathrm{xy}}$ cheio (tomando-se o eixo $\mathrm{z}$ ao longo da ligação Os-N), comparada com a blindagem no isômero trans pela ligação $\pi$ que se situa na direção do plano Os-N.

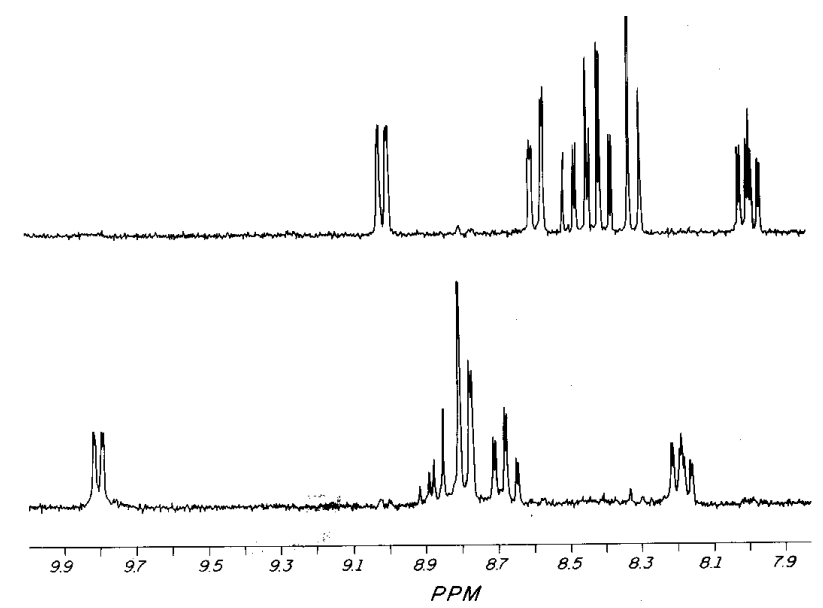

Figura 8. Espectro de $R M N{ }^{1} H$ de trans-(superior) $e$ cis-

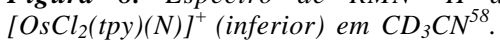

Nos demais prótons dos anéis as mudanças nos seus deslocamentos químicos ocorrem, mas não de maneira tão acentuada ${ }^{58}$.

Em suma, as características inerentes a cada série isomérica investigada permitem que os complexos sejam caracterizados e tenham as suas propriedades analisadas pelas mais variadas combinações de técnicas. Além da espectroscopia de absorção na região do infravermelho e de ressonância magnética multinuclear, que são sobejamente usadas ${ }^{59-65}$, podemos citar também dados extraídos de espectroscopia Raman ${ }^{2}$, espectroscopia de absorção na região do ultravioleta/visível ${ }^{66}$, espectroscopia de massa $^{67}$, análise térmica ${ }^{6,69}$, ressonância paramagnética eletrônica $^{37}$, voltametria cíclica ${ }^{34,57}$ e técnicas de raios $\mathrm{X}^{11,70}$, como de grande valia na distinção entre isômeros geométricos e no estudo das propriedades dos mesmos. Obviamente algumas destas técnicas são usadas para soluções, enquanto outras fazem uso da amostra no estado sólido.

\section{REAÇÕES DE ISOMERIZAÇÃO E PROPOSTAS MECANÍSTICAS}

Isômeros geométricos de complexos de coordenação e os mecanismos através dos quais eles se interconvertem despertam o interesse dos químicos há mais de um século ${ }^{71-73}$. As reações de isomerização podem ocorrer tanto em estado sólido quanto em solução e são estudadas com o auxílio das mais variadas técnicas ${ }^{68,74-76}$.

Entre os estudos de reações de isomerização de complexos de metais do grupo da platina destacam-se aqueles referentes aos complexos fosfínicos quadrado planares de $\mathrm{Pd}(\mathrm{II})$ e $\mathrm{Pt}(\mathrm{II})$ que vêm sendo realizados há aproximadamente meio século ${ }^{77-82}$ e despertam grande interesse devido, em parte, à importância destes metais e dos seus complexos como catalisadores ${ }^{83}$. Tomando por base os dados extraídos destas investigações algumas observações sobre a ocorrência e estabilidade termodinâmica dos isômeros geométricos cis e trans de complexos do tipo $\left[\mathrm{MX}_{2} \mathrm{~L}_{2}\right],(\mathrm{M}=\mathrm{Pd}, \mathrm{Pt} ; \mathrm{X}=$ ligantes aniônicos; $\mathrm{L}=$ ligantes neutros) foram reportadas ${ }^{16,72,77-83}$. Verificou-se, por exemplo, que via de regra os isômeros cis são entalpicamente favorecidos, enquanto que fatores entrópicos favorecem a forma trans em solução e que estes fatores termodinâmicos são finamente balanceados, permitindo a observação de ambos os isômeros de muitos compostos em solução. Mudanças de metal, ligante, solvente ou temperatura podem afetar substancialmente a posição de equilíbrio do sistema, tornando evidente que muitos aspectos inter-relacionados contribuem para a estabilidade de cada isômero.

Um estudo abrangente sobre a isomerização cis-trans de complexos quadrado planares de paládio e platina foi realizado 
por Chatt e Wilkins em meados dos anos $50^{77-80}$ e foi de grande valia para o entendimento do favorecimento de uma dada configuração cis ou trans em um par isomérico, dependendo dos ligantes presentes na esfera de coordenação do metal. Estes pesquisadores determinaram as constantes de equilíbrio para a isomerização

$$
\text { cis- }\left[\left(\mathrm{LR}_{3}\right) \mathrm{PtX} \mathrm{P}_{2}\right] \leftrightarrow \text { trans }-\left[\left(\mathrm{LR}_{3}\right)_{2} \mathrm{PtX}{ }_{2}\right]
$$

$(\mathrm{R}=$ radical hidrocarboneto, $\mathrm{L}=\mathrm{P}, \mathrm{As}, \mathrm{Sb}$ e $\mathrm{X}=\mathrm{Cl}$ ou $\mathrm{I})$

e verificaram que o equilíbrio químico desloca-se para a direita quando:

- grupos $\mathrm{R}$ fenilas são trocados por grupos alquilas nos ligantes do tipo $\mathrm{LR}_{3}$; sugerindo que o deslocamento do equilíbrio químico para a direita deva-se a fatores estéricos, uma vez que os rígidos grupos fenilas ocupam menor espaço na vizinhança do átomo $L$ do que os grupos alquilas. Não se elimina, todavia, a hipótese de que este deslocamento ocorra devido também a efeitos eletrônicos. A maior eletronegatividade dos grupos fenila, quando comparado com os grupos alquila pode aumentar a força da ligação $\pi$ entre o átomo L e o átomo da platina, acentuando a estabilidade do isômero cis com relação ao isômero trans $^{72,80}$.

- a série homóloga é ascendente em termos de volume, de R $=$ Me para $\operatorname{Pr}^{\mathrm{n}}$. Novamente atribui-se a maior estabilização do isômero trans com relação ao isômero cis a fatores estéricos, uma vez que a diferença entre efeitos eletrônicos dos grupos alquilas nestes compostos é pequena ${ }^{72,80}$.

- L é substituído na ordem Sb, P e As. A configuração cis é altamente favorecida se $\mathrm{L}$ é trocado na ordem $\mathrm{As}<\mathrm{P} \leq \mathrm{Sb}$. A diferença entre a série de compostos de arsênio e fósforo é devida à mudança no calor de isomerização, porém entre a série de fósforo e estibina é causada pela mudança de entropia e não de $\Delta \mathrm{H}$. A maior concentração do isômero cis na série de complexos de platina contendo estibina devese a uma menor diferença de entropia entre os isômeros nesta série do que entre os isômeros nas séries correspondentes de fósforo e $\operatorname{arsina}^{72,78}$.

- o cloreto é trocado por iodeto. Isto deve-se provavelmente ao fato da maior força de ligação da Pt-I quando comparada com Pt-Cl, o que significa que a ligação Pt-L contribui mais para a força de ligação total no composto de iodo que naquele de cloro. Deve-se considerar também que o $\mathrm{I}^{-}$ apresenta maiores propriedades $\sigma$ e $\pi$ que o $\mathrm{Cl}^{-}$. Estes aspectos, em seu conjunto, fazem com que os compostos contendo o iodo sejam menos polares (as ligações L-Pt-X sejam de intensidades próximas) que seus correspondentes compostos contendo cloro (as ligações L-Pt-X sejam de intensidades bem diferentes), o que, pelo que foi mencionado anteriormente, conduz à formação preferencial de isômeros trans, justificando o deslocamento do equilíbrio acima para a direita.

Estudos semelhantes aos desenvolvidos por Chatt e Wilkins ${ }^{77-80}$ foram realizados por Redfiel e Nelson ${ }^{82}$, onde investigou-se o efeito do solvente no equilíbrio termodinâmico para a isomerização cis-trans dos complexos fosfínicos de paládio, $\left[\mathrm{PdCl}_{2}\left(\mathrm{PMe}_{2} \mathrm{Ph}\right)_{2}\right]$ e $\left.\left[\mathrm{PdCl}_{2} \mathrm{PMePh}_{2}\right)_{2}\right]$, e observou-se que tanto $\Delta \mathrm{H}$ como $\Delta \mathrm{S}$ apresentam contribuições na solvatação de isômeros cis-trans. Deve-se ressaltar que há duas contribuições principais tanto para $\Delta \mathrm{H}$ como para $\Delta \mathrm{S}$. Para $\Delta \mathrm{H}$ estas são $\Delta H$ nas alterações das forças de ligações internas e $\Delta H$ de solvatação. Ambas contribuições favorecem o isômero cis, pois:

- as ligações paládio-fósforo devem ser mais fortes nos isômeros cis que nos isômeros trans.

Esta afirmação deve-se ao fato de que átomos de fósforo têm maior tendência de formar ligações $\pi$ com os metais que o cloro. Isto permite concluir que os isômeros que apresentam maior quantidade de ligações com caráter de dupla, M-P, devem apresentar maior força de ligação global, o que deve recair sobre os isômeros cis, nos quais os átomos de fósforo encontram-se trans aos átomos de cloro, $\mathrm{P}-\mathrm{M}-\mathrm{Cl}$ e competem com estes cloretos em relação aos elétrons dos orbitais d do metal. Tal competição favorece grandemente a delocalização da densidade eletrônica do metal para os ligantes fosfínicos que são melhores $\pi$ receptores que os cloretos e conseqüentemente formam ligações $\pi$ mais fortes. Esta contribuição para a força de ligação total deve ser menor nos isômeros trans, onde os ligantes fosfínicos competem um com o outro pelos mesmos elétrons do orbital d do íon metálico ${ }^{82}$.

Estima-se que a energia de ligação total dos isômeros cis de $\mathrm{Pt}(\mathrm{II})$ e $\mathrm{Pd}(\mathrm{II})$ é aproximadamente $10 \mathrm{kcal}$ mais alta que aquela dos correspondentes isômeros trans $^{72}$.

- $\quad$ os isômeros cis apresentam momentos dipolares altos $(\approx 10.7$ D) e os isômeros trans apresentam momento dipolar zero ${ }^{77}$ e, neste caso, as interações dipolo-dipolo entre os complexos e os solventes devem ser maiores no isômero cis que no isômero trans. Esta diferença de polarizabilidade resulta numa maior solvatação dos isômeros cis em relação aos isômeros trans, de forma que durante o processo de isomerização cis-trans ocorra desolvatação do solvente. Deve-se ressaltar que este processo é exotérmico e algo da ordem de duas moléculas de benzeno são liberadas por mol do isômero cis de $\mathrm{Pt}(\mathrm{II})$ convertido para a forma trans sendo que aproximadamente 2500 calorias são absorvidas ${ }^{77-82}$.

Para $\Delta S$ as contribuições principais são $\Delta S$ de solvatação e $\Delta S$ de efeito estérico interno. Desde que $\Delta S$ de efeito estérico interno deve ser pequeno, pois envolve apenas a perda de alguns graus de liberdade rotacionais e vibracionais, o termo $\Delta \mathrm{S}$ de solvatação deve ser o termo mais significante ${ }^{81}$.

Em vista das razões acima descritas, $\Delta \mathrm{S}$ favorece a geometria trans e $\Delta \mathrm{H}$ favorece a geometria cis e desde que ambos os termos são dominados por interações dipolo-dipolo entre o solvente e o complexo, as espécies trans devem ser as mais abundantes em solventes com mais baixos momentos dipolares. Isto significa que os isômeros trans apresentam pouca afinidade pelas moléculas dos solventes, ocasionando mais baixos valores de $\Delta \mathrm{S}$. Neste caso é provável que o momento dipolar do solvente seja o fator mais importante e determinante na geometria do complexo em solução ${ }^{82}$. Em outras palavras, para efeito prático, pode-se dizer que isômeros cis quadrado planares de $\mathrm{Pd}(\mathrm{II})$ e $\mathrm{Pt}$ (II) com fosfinas são geralmente muito menos solúveis que os isômeros trans em solventes não polares ou pouco polares, tais como éter dietílico ou éter de petróleo, por exemplo, porém dissolvem-se um pouco em benzeno, provavelmente devido a relativa planaridade e possibilidade de polarização das moléculas do $\mathrm{C}_{6} \mathrm{H}_{6}$, as quais podem associar-se com as também planas moléculas dos complexos ${ }^{77-82}$.

Desde os estudos desenvolvidos por Chatt e Wilkins ${ }^{77-80}$, os quais fundamentam processos de isomeria cis-trans em complexos quadrado planares, uma infinidade de novos trabalhos sobre reações de isomerização deste tipo foram reportados na literatura, indicando um constante interesse por estes sistemas ${ }^{15,30,38}$. Assim, a investigação da isomerização cis-trans do complexo bis(pentafluorofenil)bis(tetraidrotiofeno)paládio(II), $\left[\mathrm{Pd}\left(\mathrm{C}_{6} \mathrm{~F}_{5}\right)_{2}(\mathrm{tht})_{2}\right]$, realizado por Minniti ${ }^{35}$, que relataremos a seguir, é apenas um exemplo recente, entre muitos outros, encontrado na literatura ${ }^{14,17}$. Os complexos cis-e trans-[Pd $\left.\left(\mathrm{C}_{6} \mathrm{~F}_{5}\right)_{2}(\mathrm{tht})_{2}\right]$ (tht $=$ tetraidrotiofeno) isomerizam-se espontaneamente em clorofórmio, levando a uma mistura de equilíbrio, onde a espécie cis é a predominante. A constante de velocidade de primeira ordem, para a isomerização neste sistema, $\mathrm{K}_{\mathrm{tc}}$, e a constante de equilíbrio, $K_{\mathrm{eq}}$, foram medidas em diferentes temperaturas, por ressonância magnética nuclear de próton. A isomerização sofre retardo pela adição de tht e é caracterizada 
por um alto valor de entalpia de ativação $\left(\Delta \mathrm{H}_{\mathrm{tc}}{ }^{\#}=137 \pm 6 \mathrm{~kJ}\right.$ $\left.\mathrm{mol}^{-1}\right)$ e um valor positivo grande, de entropia de ativação $\left(\Delta \mathrm{S}_{\mathrm{tc}}\right.$ \# $\left.=83 \pm 19 \mathrm{~J} \mathrm{~K}^{-1} \mathrm{~mol}^{-1}\right)$. O mecanismo de isomerização para este sistema foi possível de ser sugerido quando foi realizada a substituição do tht por 2-metilpiridina em trans- $\left[\mathrm{Pd}\left(\mathrm{C}_{6} \mathrm{~F}_{5}\right)_{2}(\text { tht })_{2}\right]$ a qual é caracterizada por uma baixa entalpia de ativação $\left(\Delta \mathrm{H}_{\mathrm{N}}{ }^{\#}=\right.$ $\left.51 \pm 2 \mathrm{~kJ} \mathrm{~mol}^{-1}\right)$ e uma entropia negativa de ativação $\left(\Delta \mathrm{S}_{\mathrm{N}}{ }^{\#}=\right.$ $\left.114 \pm 4 \mathrm{~J} \mathrm{~K}^{-1} \mathrm{~mol}^{-1}\right)$. O alto valor da entalpia de ativação e o grande valor da entropia de ativação observados no processo de isomerização, em contraste com a baixa entalpia e entropia de ativação negativa encontrados para a reação de substituição do trans- $\left[\mathrm{Pd}\left(\mathrm{C}_{6} \mathrm{~F}_{5}\right)_{2}(\text { tht })_{2}\right]$ suportam a sugestão de quebra da ligação M-tht, proposta no esquema 1 abaixo, envolvendo a perda dissociativa do tht e a interconversão de dois intermediários geometricamente distintos tricoordenados ${ }^{35}$

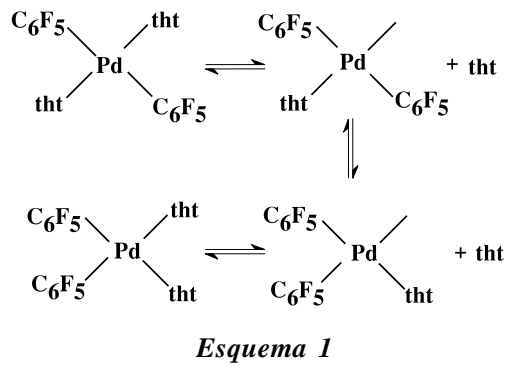

Os demais elementos do grupo da platina também são alvo de grande interesse no que diz respeito ao estudo de isomerização onde verifica-se que as reações de isomerização térmicas são as mais freqüentemente reportadas, podendo-se citar como exemplo o recente processo de isomerização do complexo $\left[\mathrm{H}(\mathrm{dmso})_{2}\right]\left[\right.$ trans $\left.-\mathrm{RhCl}_{4}(\mathrm{dmso}-\mathrm{S})_{2}\right]$ para o correspondente isômero cis, estudado por Alessio e colaboradores ${ }^{36}$. A isomerização térmica foi seguida espectrofotometricamente e um ponto isosbéstico a $512 \mathrm{~nm}$ foi mantido durante o processo. As constantes de velocidades para este processo foram determinadas a 6 temperaturas na faixa de $35-60^{\circ} \mathrm{C}$ e os parâmetros de ativação foram calculados: $\Delta \mathrm{H}^{\neq}=93 \pm 3 \mathrm{~kJ} \mathrm{~mol}^{-1} ; \Delta \mathrm{S}^{\neq}=-21$ $\pm 6 \mathrm{JK}^{-1} \mathrm{~mol}^{-1} ; k_{25 \mathrm{C}}=2,15 \times 10^{-5} \mathrm{~s}^{-1}$. Um mecanismo de isomerização envolvendo a dissociação de um dos mutualmente trans dmso-S como um primeiro passo, seguido pela reorganização de um intermediário pentacoordenado e recoordenação do dmso-S, em posição cis, foi proposto pelos autores.

Para os complexos de rutênio contendo monofosfinas estudados por Krassowski e colaboradores ${ }^{20}$ (Figura 7), verificou-se igualmente um processo de isomerização térmica. O complexo com todos os pares de ligantes em trans $(\mathbf{t t t})$, isomeriza-se termicamente em solução ao isômero ccc. Este isômero ccc também isomeriza-se em solução produzindo a espécie cct, com apenas os ligantes fosfínicos mutualmente em trans. A estabilidade termodinâmica relativa dos três isômeros pode ser atribuída à orientação dos ligantes em cada complexo. Uma vez que o mecanismo de reação mais comum de complexos carbonilo metálicos é a dissociação inicial do $\mathrm{CO}^{84}$, o efeito das mudanças nas posições dos ligantes no complexo são de grande importância. Quando dois ligantes CO estão mutuamente em trans, eles competem pela densidade eletrônica presente no mesmo orbital $\mathrm{d}$ do metal e a retrodoação $\mathrm{M} \rightarrow \mathrm{C}$ é reduzida (o $\mathrm{CO}$ é um receptor $\pi$ muito bom). Assim, ligantes $\mathrm{CO}$ em posição trans tendem a labilizar um ao outro ${ }^{85}$. Considerando que as fosfinas não são usualmente bons $\pi$ receptores ${ }^{86}$ e os ligantes $\mathrm{Cl}$ são menos ainda, a influência trans com relação ao CO diminui na ordem $\mathrm{CO}>\mathrm{P}>\mathrm{Cl}$. Por isto, no isômero ccc a perda do $\mathrm{CO}$ trans à fosfina é mais difícil de ocorrer do que no isômero ttt. As ligações M-CO trans a $\mathrm{Cl}$ no isômero cct são ainda mais fortes e provavelmente contribuem para que este isômero apresente-se como o produto termodinamicamente preferido desta série ${ }^{20}$.
A referida interconversão entre os isômeros ttt e cct , quando $\mathrm{P}=\mathrm{BzI}_{3} \mathrm{P}, \mathrm{Ph}_{3} \mathrm{P}, \mathrm{Ph}_{2} \mathrm{MeP}, \mathrm{PhMe}_{2} \mathrm{P}, \mathrm{Me}_{3} \mathrm{P}$, foi seguida observando-se as mudanças do estiramento $\mathrm{CO}$ na região do infravermelho, onde o decréscimo inicial na absorção do isômero ttt é acompanhado por um aumento na absorção devida ao isômero intermediário ccc. Esta absorção ccc diminui vagarosamente com o aumento da absorção do produto final cet. Os parâmetros de ativação para estes processos de isomerização foram determinados encontrando-se valores positivos de $\Delta \mathrm{H}^{\neq} \mathrm{e} \Delta \mathrm{S}^{\neq}$, indicativos de mecanismo dissociativo para isomerização de complexos hexacoordenados ${ }^{72,73}$. Um suporte adicional para a proposta do mecanismo dissociativo foi fornecido pela constatação de que a velocidade de isomerização aumenta com o aumento do volume estérico da fosfina e é retardado por excesso de monóxido de carbono no meio reacional ${ }^{20}$.

$\mathrm{O}$ mecanismo proposto para a isomerização dos complexos $\left[\mathrm{RuCl}_{2}(\mathrm{CO})_{2} \mathrm{P}_{2}\right]$ encontra-se ilustrado no esquema 2 . A perda do $\mathrm{CO}$ é o passo inicial e a espécie pentacoordenada formada inicialmente pode reagir de três maneiras : (1) ataque do $\mathrm{CO}$ trans ao CO gerando o complexo de partida; (2) formação direta do produto da isomerização cet pelo ataque do $\mathrm{CO}$ trans ao cloreto; (3) pseudorotação de Berry levando a uma outra espécie pentacoordenada $5 \mathrm{C}$, que conduz ao isômero ccc (rápida) ou cct (lenta).

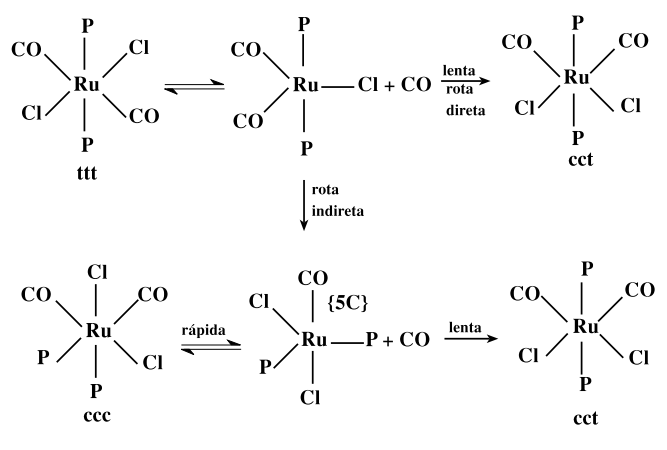

Esquema 2

Assim como para os complexos de paládio estudados por Redfield e Nelson ${ }^{82}$ também a influência do solvente na isomerização cis-trans do complexo $\left[\mathrm{OsCl}_{2}(\text { tpy })(\mathrm{N})\right]^{+}$, onde tpy $=$ $2,2^{\prime}: 6^{\prime}, 2^{\prime \prime} \leq-$ terpiridina, foi observada por Meyer e colaboradores $^{58}$. Ambos os isômeros cis- e trans- $\left[\mathrm{OsCl}_{2}(\mathrm{tpy})(\mathrm{N})\right]^{+}{ }^{(\text {cis-trans }}$ em relação aos cloretos) são estáveis em diclorometano. No entanto, a isomerização ocorre se metanol é adicionado ao diclorometano, podendo-se sugerir que um solvente potencialmente coordenante $\left(\mathrm{CH}_{3} \mathrm{CN}, \mathrm{CH}_{3} \mathrm{OH}, \mathrm{H}_{2} \mathrm{O}\right)$ faz-se necessário para que o processo de isomerização ocorra. Neste caso sugere-se que o solvente funciona como ligante neste processo de isomerização.

Exemplos de isômeros que podem ser interconvertidos tanto fotoquímica quanto termoquimicamente são também reportados na literatura para complexos de metais do grupo da plati$\mathrm{na}^{36,87,88}$ e citamos os compostos de fórmula geral $\left[\mathrm{RuCl}_{2}(\mathrm{~N}-\right.$ $\mathrm{N})(\mathrm{dppb})]$, onde dppb = 1,4-bis(difenilfosfina)butano; $\mathrm{N}-\mathrm{N}=$ 1,10-fenantrolina, 4,7-difenil-1,10-fenantrolina, 2,2'-bipiridina e 2,2'-bipiridilamina, recentemente sintetizados, como detentores destas características ${ }^{89-91}$. A interconversão fotoquímica foi seguida por experimentos de voltametria cíclica e RMN ${ }^{31} \mathrm{P}\left\{{ }^{1} \mathrm{H}\right\}$ e verificou-se que após um período de 2 horas, sob luz solar, os isômeros trans são levados aos isômeros cis. A ocorrência de isomerização foi também constatada via térmica, refluxando-se os isômeros trans em diclorometano, durante 48 horas, na ausência de luz ${ }^{89-91}$.

Um estudo sobre a conversão do isômero $c i s-\left[\mathrm{RuCl}_{2}(\mathrm{dppm})_{2}\right]$ ao trans- $\left[\mathrm{RuCl}_{2}(\mathrm{dppm})_{2}\right]$, induzido por processo redox, foi relatado por Sullivan e colaboradores ${ }^{33}$. Outros estudos similares 
foram relatados por Chakravorty e colaboradores ${ }^{92,93}$ com complexos do tipo cis- $\left[\mathrm{Ru}\left(\mathrm{ROCS}_{2}\right)_{2}\left(\mathrm{PPh}_{3}\right)_{2}\right]$ e cis- $\left[\mathrm{Os}\left(\mathrm{RSCS}_{2}\right)_{2}\right.$ $\left.\left(\mathrm{PPh}_{3}\right)_{2}\right]\left(\mathrm{R}=\mathrm{Et}, \mathrm{Pr}^{\mathrm{i}}\right.$ ou $\left.\mathrm{PhCH}_{2}\right)$ e por Ballester e colaboradores $^{94}$ com complexos do tipo cis- $\left[\mathrm{Ru}(\mathrm{S}, \mathrm{S})(\mathrm{L})_{2}\right], \mathrm{S}-\mathrm{S}=\mathrm{EtCOCS}_{2}$, $\left(\mathrm{CH}_{2}\right)_{4} \mathrm{NCS}^{-} ; \mathrm{L}=$ monofosfina, dppm [bis(difenilfosfina) metano] ou dppe [1,2 -bis(difenilfosfina)etano].

Mais recentemente Batista e colaboradores ${ }^{37}$ reportaram a síntese e caracterização do par isomérico cis,trans- $\left[\mathrm{RuCl}_{2}\right.$ (dppen $\left.)_{2}\right]$, onde dppen $=1,2$-bis [cis(difenilfosfina) etileno $]$. $\mathrm{Na}$ figura 9 encontram-se o voltamograma cíclico e o voltamograma de pulso diferencial obtidos para esta mistura de isômeros. Os dois processos redox observados, com valores de $\mathrm{E}_{1 / 2}, 0,54$ $\mathrm{V}$ (picos 1 e 4) e $0,92 \mathrm{~V}$ (picos 2 e 3), foram considerados como reversíveis, para os isômeros trans e cis, respectivamente. As estabilidades química e eletroquímica destes isômeros, em solução, foram analisadas por meio de eletrólises a potencial controlado de uma solução milimolar da mistura de isômeros. Estas eletrólises foram monitoradas por voltametria cíclica e espectroscopia de ressonância paramagnética eletrônica. Após uma primeira eletrólise anódica, a 0,80 V (potencial superior ao do pico 1) monitorada por voltametria cíclica , observou-se que as intensidades de corrente anódica e catódica do primeiro processo redox (picos 1 e 4) tornaram-se superiores às iniciais, enquanto que as do segundo processo redox (picos 2 e 3) tornaram-se consideravelmente menos intensas que as observadas inicialmente. $\mathrm{O}$ fato das correntes anódica e catódica dos picos 2 e 3 terem diminuído e as dos picos 1 e 4 terem aumentado após a eletrólise realizada a $0,80 \mathrm{~V}$, indicou que na solução em estudo a concentração do isômero cis oxidado diminuiu e a do isômero trans aumentou. Isto sugere que o isômero cis oxidado é instável e isomeriza-se à forma trans. De fato, após uma segunda eletrólise anódica, desta vez a 1,10 $\mathrm{V}$ (potencial superior ao do pico 2), observou-se que as intensidades de corrente anódica e catódica dos picos 1 e 4 aumentaram mais ainda, em relação à observada anteriormente, e os picos 2 e 3 desapareceram por completo. A comparação entre os valores das correntes de pico dos processos redox após eletrólise anódica a 0,80 e $1,10 \mathrm{~V}$, indicou que realmente o isômero cis foi quantitativamente convertido no trans durante a eletrólise.

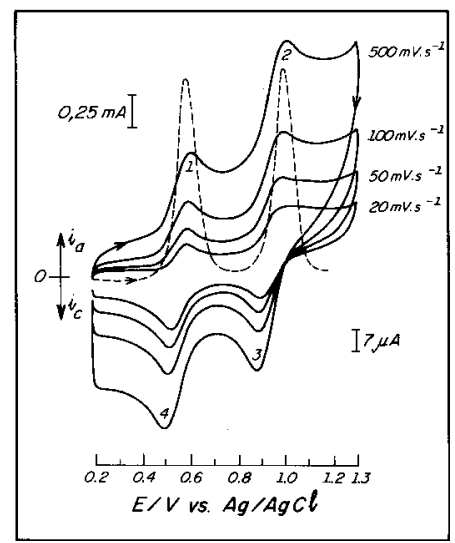

Figura 9. Voltamograma cíclico (-) e voltamograma de pulso diferencial (---) obtidos para a mistura de isômeros trans-(picos 1 e 4) e cis-(picos 2 e 3) do [RuCl $\left.{ }_{2}(\text { dppen })_{2}\right] 1 \times 10^{-3} \mathrm{~mol} / \mathrm{L}$ em PTBA 0,1 mol / $\mathrm{L} \mathrm{em} \mathrm{CH}_{2} \mathrm{Cl}_{2}$. Eletrodo de referência $\mathrm{Ag} / \mathrm{AgCl}$, eletrodo de trabalho e auxiliar, placas de Pt. Nas condições de trabalho o Ferroceno é oxidado ao potencial de $0,48 \mathrm{~V}^{37}$.

\section{CONCLUSÕES}

Esta breve revisão sobre isômeros cis-trans permite-nos as seguintes conclusões:
1) Diferentes isômeros podem apresentar distintas propriedades físicas e/ou químicas e mudanças de metal, ligante, solvente ou temperatura de reação podem conduzir à formação preferencial de um dado isômero;

2) A obtenção de compostos puros é dificultada pelo desconhecimento, a priori, das rigorosas condições reacionais que podem conduzir à sintese seletiva de um ou outro isômero específico ou mesmo pela dificuldade em isolá-los de misturas;

3) Embora mecanismos de isomerização sejam propostos, muitos deles são feitos de forma mais intuitiva que fundamentada em dados experimentais, os quais às vezes são muito difíceis de serem observados dada a dificuldade de obtenção de evidências concretas que comprovem as sugestões propostas.

\section{AGRADECIMENTOS}

Os autores agradecem à FAPESP e CNPq pelos auxílios financeiros e aos Profs. Drs. Antônio Gilberto Ferreira (DQ-UFSCar) e Sérgio de Paula Machado (IQ-UFRJ) pelas sugestões.

\section{REFERÊNCIAS}

1. Gerber, T. I. A.; Kemp, H.J.; Preez, J. G. H.; J. Coord. Chem. 1994, 33, 171.

2. Brickleband, N.; Godfrey, S. M.; McAuliffe, C. A.; Molloy, K. C.; J. Chem. Soc., Dalton Trans. 1995, 10, 1593.

3. Nakazawa, H.; Yamaguchi, Y.; Mizuta,T.; Miyoshi, K.; Organometallics 1995, 14, 4173.

4. Barnard, C. F. J.; Vollano, J. F.; Chaloner, P. A.; Dewa, S. L.; Inorg. Chem. 1996, 35, 3280..

5. Wehman-Ooyevaar, I. C. M.; Drenth, W.; Grove, D. M.; Koten, G.; Inorg. Chem. 1993 , 32, 3347.

6. Favez, R.; Roulet, R.; Pinkerton, A.; Schwarzenbach, D.; Inorg. Chem. 1980, 19, 1356.

7. Al-Najjar, I. M.; Al-Lohedan, H. A.; Issa, Z. A.; Inorg. Chim. Acta 1988, 143, 119.

8. Kauffman, G. B.; Coord. Chem. Rev. 1973, 11, 161.

9. Springer, C. S.; Sievers, R. E.; Inorg. Chem. 1967, 6, 852.

10. Muetterties, E. L.; J. Am. Chem. Soc. 1968, 90, 5097.

11. Svensson, P.; Lovqvist, K.; Kukushkin, V.Y.; Oskarsson, A.; Acta Chem. Scand. 1995, 49, 72.

12. Sullivan, B. P.; Calvert, J. M.; Meyer, T. J.; Inorg. Chem. 1980, 19, 1404.

13. Isied, S.S.; Taube, H.; Inorg. Chem. 1976, 12, 3070.

14. Romeo, R.; Minniti, D.; Trozzi, M.; Inorg. Chem. 1976, 15,1134

15. Alibrandi, G.; Scolaro, L. M.; Romeo, R.; Inorg. Chem. 1991, 30, 4007.

16. Anderson, G.K.; Cross, R. J.; Chem. Soc. Rev. 1980, 9 , 185 .

17. Alibrandi, G.; Minniti, D.; Scolaro, L. M.; Romeo, R.; Inorg. Chem. 1988, 27, 318.

18. Farrel, N.; Transition Metal Complexes as Drug and Chemotherapeutic Agents; Kluwer Academic, Dordrecht, 1989.

19. Gill, D. S.; Platinum Coordination Complexes in Cancer Chemotherapy; Martinus Nijhoff, Boston, 1984.

20. Krassowski, D.W.; Nelson, J. H.; Brower, K. R.; Hauenstein, D.; Jacobson, R. A.; Inorg. Chem. 1988, 27, 4294.

21. Batista, A. A.; Olmo, L. R. V.; Fontes, M. R. M.; Oliva, G.; J. Braz. Chem. Soc. 1996, 7, 257.

22. Berzelius, J. J.; Jahresbericht Åber die Fortschritte der physischen Wissenchaften 1831, 11, 4.

23. Purcell, K. F. ; Koltz, J. C.; Inorganic Chemistry, HoltSaunders International Editions, 1977.

24. Shriver, D. F.; Atkins, P. W.; Langford, C. H.; Inorganic Chemistry, Oxford University Press, Oxford, 1991. 
25. Pramanik, A.; Bag, N.; Chakravorty, A.; Inorg. Chem. 1993, 32, 811 .

26. Bottomley, F.; Lin, I. J. B.; Mukaida, M.; Patterson, J. L.; J. Chem. Soc. Dalton Trans. 1980, 487.

27. De Klerk-Engels, B.; Fruhauf, H.; Vrieze, K.; Kooijman, H.; Spek, A. L.; Inorg. Chem. 1993, 32, 5528.

28. Alcock, N. W.; Platt, W.; Pringle, P. G.; J. Chem. Soc. Dalton Trans. 1989, 2069.

29. Osakada, K.; Hataya, K.; Yamamoto, T.; Inorg. Chem. 1993, 32, 2360 .

30. Fraccarollo, D.; Bertani, R.; Mazzon, M.; Belluco, U.; Michelin, R. A.; Inorg. Chim. Acta 1992, 201, 15.

31. Nicolini, M.; Platinum and Other Metal Coordination Compounds in Cancer Chemotherapy; Martinus Nijhoff Publishing: Bosaton, MA, 1988.

32. Beyerle-Pfnur, R.; Brown, B.; Faggiani, R.; Lippert, B.; Lock, C. J. L.; Inorg. Chem. 1985, 24, 4001.

33. Sullivan, P. B.; Meyer, T. J.; Inorg. Chem. 1982, 21, 1037.

34. Alibrandi, G.; Scolaro, L. M.; Romeo, R.; Inorg. Chem. 1991, 30, 4007.

35. Minniti, D.; Inorg. Chem. 1994, 33, 2631.

36. Alessio, E.; Santi, A.S.; Faleschini, P.; Calligaris, M.; Mestroni, G.; J. Chem. Soc., Dalton Trans. 1994, 1849.

37. Batista, A. A.; Cordeiro, L. A. C.; Oliva, G.; Nascimento, O. R.; Inorg. Chim. Acta 1997, 258, 131.

38. Murdoch, P. S.; Ranford, J. D.; Sadler, P. J.; BernersPrice, S. J.; Inorg. Chem. 1993, 32, 2249.

39. Fukuchi, T.; Miki, E.; Mizumachi, K.; Ishimori, T.; Chem. Lett. 1987, 1133.

40. Simonsen, K.; Hamada, M.; Suzuki, N.; Kojima, M.; Ohba, S.; Galsbol, F.; Saito, Y.; Fujita, J.; Bull. Chem Soc. Jpn. 1990, 63, 2904.

41. Celap, M. B.; Vuckovic, G.; Malinar, M. J.; Janjic, T. J.; Radivojsa, P. N.; J. Chromatogr. 1980, 196, 59.

42. Vuckovic, G.; Janjic, T. J.; Tesic, Z. L.; Celap, M. B.; J. Chromatogr. 1985, 324, 431.

43. Kauffman, G. B.; J. Chem. Ed. 1966, 43, 677.

44. Kong, P.; Rochon, F. D.; Can. J. Chem. 1981, 59, 3293.

45. During, J. R.; Mitchell, B. R.; Sink, D. W.; Willis, J. N.; Spectrochim. Acta 1967, 23A, 1121.

46. Nakamoto, K.; Infrared and Raman Spectra of Inorganic and Coordination Compounds, Wiley, New York, 1986.

47. Walton, M. A.; Can. J. Chem. 1968, 46, 2348.

48. Walton, M. A.; Spectrochim. Acta 1965, 21, 1795.

49. Neuse, E. W.; Perlwitz, A. G.; Field, J. S.; Ramesar, N.; Transition Met. Chem. 1995, 20, 62.

50. Ha, T.B.T.; Souchard, J. P.; Wimmer, F. L.; Johnson, N. P.; Polyhedron 1990, 9, 2647; e referências aí contidas.

51. Pidcock, A.; Richards, R. E.; Venanzi, L.; Proc. Chem. Soc., London 1962 , 184.

52. Grim, S. O.; Keiter, R. L.; McFarland, E.; Inorg. Chem. 1967, 6, 1133.

53. Holt, M. S.; Nelson, J. H.; Inorg. Chem. 1986, 25, 1316.

54. Walton, R. A.; Whyman, R.; J.Chem. Soc. A 1968, 1394.

55. Wilkes, L. M.; Nelson, J. H.; Mitchener, J. P.; Babich, M. W.; Riley, W. C.; Helland, B. J.; Jacobson, R. A.; Cheng, M. Y.; Seff, K.; McCusker, L. B.; Inorg. Chem. 1982, 21, 1376.

56. Verstiyf, A. W.; Redfield, D. A.; Cary, L. W.; Nelson, J. H.; Inorg. Chem. 1977, 16, 2776 e referências aí contidas.

57. Dobson, J. C.; Takeuchi, K. J.; Pipes, D.W.; Geslowitz, D. A.; Meyer, T. J.; Inorg. Chem. 1986, 25, 2357.

58. Williams, D. S.; Coia, G. M.; Meyer, T. J.; Inorg. Chem. 1995, 34, 586

59. Hasegawa, T.; Lau, T.C.; Taube, H.; Schaefer, W.P.; Inorg. Chem. 1991, 30, 2921.

60. Batheja, R.; Dhingra, S.K.; Singh, A. K.; J. Organomet. Chem. 1995, 496, 99.
61. Hill, W. E.; Taylor, J. G.; Falsaw, C. P.; King,T. J.; Beagley, B.; Tonge, D. M.; Pritchard, R. G.; C. A.; J. Chem. Soc. Dalton Trans. 1986, 2289. McAuliffe

62. Kuroda, R.; Stephen, N.; Ismail, I. M.; Sadler, P. J.; Inorg. Chem. 1983, 22, 3620.

63. Dahlenburg, I.; Mirzael, F.; Pietsch, B.; Inorg. Chim. Acta, 1985, 97, L5.

64. Blake, A. J.; Champness, R. J. F.; Frampton, C. S.; Frost, C. A.; Gillian, R.; Simpson, R. H.; J. Chem. Soc. Dalton Trans. 1994, 3377.

65. Cini, R.; Caputo, P. A.; Intini, F. P.; Natile, G.; Inorg. Chem. 1995, 34, 1130.

66. Tse, Y.; Auburn, P. R.; Lever, A. B. P.; Can. J. Chem. 1992, 70, 1849.

67. Miki, E.; Masano, H.; Iwasaki, H.; Tomizawa, H.; Mizumachi, K.; Ishimori, T.; Tanaka, M.; Nagai, T.; Nagao, N.; Inorg. Chim. Acta 1993, 205, 129.

68. Macdonald, F.; Sadler, P. J.; Polyhedron, 1991, 10, 1443.

69. Roe, S. P.; Hill, J. O.; Magee, R. J.; Inorg. Chem. Acta 1986, 115, L15.

70. Lawson, H. J.; Janik, T. S.; Churchill, M. R.; Takeuchi, K. J.; Inorg. Chem. Acta 1990, 174, 197.

71. Jorgensen, C. K.; J. Prakt. Chem. 1889, 39,16.

72. Basolo, F.; Pearson, R. G.; Mechanisms of Inorg. Reactions; John Wiley, New York, 1968.

73. Wilkins, R. G.; Kinetics and Mechanis of Reactions of Transition Metal Complexes; VCH, Weinhheim, Germany, 1991.

74. Tomizawa, H.; Miki, E.; Mizumachi, K.; Ishimori, T.; Bull. Chem. Soc. Jpn. 1994, 67,1809.

75. Ikezawa, H.; Miki, E.; Mizumachi, K.; Ishimori, T.; Wakatsuki, Y.; Chem. Lett. 1993, 537.

76. Koch, K.R.; Inorg. Chim. Acta 1988, 147, 227.

77. Chatt, J.; Wilkins, R. G.; J. Chem. Soc. 1952, 273.

78. Chatt, J.; Wilkins, R. G.; J. Chem. Soc. 1952, 4300.

79. Chatt, J.; Wilkins, R. G.; J. Chem. Soc. 1953, 70.

80. Chatt, J.; Wilkins, R. G.; J. Chem. Soc. 1956, 525.

81. Price, J. H.; Birk, J. P. ; Wayland, B. B.; Inorg. Chem. 1978, 17, 2245.

82. Redfield, D. A.; Nelson, J. H.; Inorg. Chem. 1973, 12, 15.

83. Redfield, D. A.; Nelson, J. H.; Henry, R. A.; Moore, D. W.; Jonassen, H. B.; J. Am. Chem. Soc. 1974, 96, 6298.

84. Darensbourg, D. J.; Adv. Organomet. Chem. 1982, $21,113$.

85. Chatt, J.; Shaw, B. L.; Field, A. E.; J. Chem. Soc. 1964, 3466.

86. Golovin, M. N.; Rahman, M. M.; Belmonte, J. E.; Giering, W. P.; Organometallics 1985, 4, 1981.

87. Alessio, E.; Milani, B.; Mestroni, G.; Calligaris, M.; Faleschini, P.; Attia, W. M.; Inorg. Chem. Acta 1990, 177, 255.

88. Barnard, C. F. J.; Daniels, A.; Jeffery, J.; Mawby, R. J.; J. Chem. Soc. Dalton Trans. 1976, 953.

89. Queiroz, S. L.; Tese de Doutoramento, UNESP- Araraquara, 1996.

90. Queiroz, S. L.; Batista, A. A ; Gambardella, M. T. P.; Santos, R. M. A.; Oliva, G.; James, B. R.; MacFarlane, K.; Retiig, S, J.; Inorg. Chem. Acta, no prelo.

91. Batista, A. A.; Queiroz, S. L.; Oliva, G.; Santos, R. M. A.; Gambardella, M. T. P.; 5th Int. Conf. Chemistry of Platinum Metals, St. Andrews, UK, 1993, Abstr. A40.

92. Bag, N.; Lahiri, G. K.; Chakravorty, A.; J. Chem. Soc., Dalton Trans. 1990, 1557.

93. Pramanic, A.; Bag, N.; Lahiri, G. K.; Chakravorty, A.; J. Chem. Soc., Dalton Trans. 1992, 101.

94. Ballester, L.; Esteban, O.; Gutierrez, A.; Perpinam, M. F.; Ruiz-Valero, C.; Gutierrez-Pueblo, E.; Gonsalez, M. J; Polyhedron 1992, 11, 3173. 